\title{
Management of rectal cancer in Canada: an evidence-based comparison of clinical practice guidelines
}

\author{
Zuhaib M. Mir, MD \\ David Yu, MD, MSc \\ Shaila J. Merchant, MD, MSc \\ Christopher M. Booth, MD \\ Sunil V. Patel, MD, MSc
}

Accepted June 10, 2019

\author{
Correspondence to: \\ Z.M. Mir \\ Department of Surgery \\ Queen's University \\ 76 Stuart St \\ Kingston ON K7L 2 V7 \\ zuhaib.mir@queensu.ca
}

DOI: $10.1503 /$ cjs. 017518
Background: Rectal cancer requires a multidisciplinary and multimodality treatment approach. Clinical practice guidelines (CPGs) provide a framework for delivering consistent, evidence-based health care. We compared provincial/territorial CPGs across Canada to identify areas of variability and evaluate their quality.

Methods: We retrieved CPGs from Canadian organizations responsible for cancer care oversight and evaluated their quality and developmental methodology using the AGREE-II instrument. Recommendations for diagnostic and staging investigations, treatment by stage, and post-treatment surveillance of stage I-III rectal cancers were abstracted and compared.

Results: We identified 7 sets of CPGs for analysis, varying in content, presentation, quality, and year last updated. Differences were noted in locoregional staging: 4 recommended magnetic resonance imaging over endorectal ultrasonography, 2 recommended either modality, and 3 specified scenarios for one over the other. Recommendations also varied for use of staging computed tomography of the chest versus chest radiography and for surgical management and indications for transanal excision. Recommendations for neoadjuvant therapy in stage II/III disease also differed: 3 guidelines recommended long-course chemoradiation over short-course radiation therapy alone, while 3 others recommended short-course radiation in specific clinical scenarios. Adjuvant chemotherapy for stage II/III disease was uniformly recommended, with variable protocols. The use of proctosigmoidoscopy and interval/duration of endoscopic post-treatment surveillance varied among guidelines.

Conclusion: Canadian CPGs vary in their recommendations for staging, treatment, and surveillance of rectal cancer. Some of these differences reflect areas with limited definitive evidence. Consistent guidelines with uniform implementation across provinces/territories may lead to more equitable care to patients.

Contexte : Le cancer rectal requiert une approche thérapeutique multidisciplinaire et multimodalité. Les guides de pratique clinique (GPC) procurent un cadre pour assurer la prestation de soins de santé constants reposant sur des données probantes. Nous avons comparé les GPC des provinces et des territoires canadiens pour identifier les secteurs où ils varient et pour en évaluer la qualité.

Méthodes : Nous avons obtenu les GPC des organisations canadiennes responsables des soins oncologiques et nous avons évalué leur qualité et la méthodologie de leur élaboration au moyen de l'outil AGREE II (Appraisal of Guidelines for Research \& Evaluation). Nous avons extrait et comparé les recommandations en ce qui concerne les épreuves diagnostiques et la stadification, les traitements en fonction du stade et la surveillance post-thérapeutique du cancer rectal de stade I à III.

Résultats : Nous avons recensé 7 GPC aux fins de cette analyse; leur contenu, leur présentation, leur qualité et l'année de leur plus récente mise à jour variaient. Des différences ont été observées au plan de la stadification locorégionale : 4 recommandaient l'imagerie par résonnance magnétique plutôt que l'échographie endorectale, 2 recommandaient l'une ou l'autre et 3 précisaient des circonstances où utiliser l'une plutôt que l'autre. Les recommandations variaient aussi pour ce qui est de l'utilisation de la scintigraphie c. radiographie thoracique de stadification, de la prise en charge chirurgicale et des indications de l'excision transanale. Les recommandations variaient également en ce qui concerne le traitement néoadjuvant pour la maladie de stade II/III : 3 guides recommandaient un traitement par chimioradiothérapie à long terme plutôt qu'une brève radiothérapie seule, tandis que 3 autres recommandaient une radiothérapie brève dans certains cas particuliers. La chimiothérapie adjuvante pour la maladie de stade II/III était uniformément recommandée, mais les protocoles variaient. L'utilisation de la proctosigmoïdoscopie et l'intervalle/durée de la surveillance endoscopique post-thérapeutique variaient d'un guide à l'autre.

Conclusion : Les GPC canadiens varient quant à leurs recommandations pour la stadification, le traitement et la surveillance du cancer rectal. Certaines de ces différences témoignent du manque de données probantes concluantes dans certains secteurs. L'uniformisation des guides et de leur application entre les provinces et les territoires pourrait faciliter une prestation plus équitable des soins aux patients. 


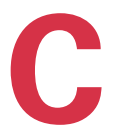

olon and rectal cancers represent $15 \%$ of all newly diagnosed cancers in Canadian men, and $12 \%$ of all newly diagnosed cancers in Canadian women. ${ }^{1}$ The detection, staging and management of rectal cancer has evolved dramatically over the last 30 years, with improved surgical techniques, involvement of multidisciplinary cancer disease site groups, and the utilization of a multimodal approach to treatment. ${ }^{2-4}$ During this time, there has been an improvement of outcomes in locoregional control and overall survival. ${ }^{5,6}$ However, with the volume and pace of evidence being generated, there remains some uncertainty and controversy regarding several elements of care, including the optimal neoadjuvant protocol, use of local excision and utility of adjuvant systemic therapy. ${ }^{5-8}$ This leads to variability in decision-making and clinical practice as well as knowledge gaps among clinicians. Previous Canadian studies have highlighted such differences among surgeons managing rectal cancer across the country. ${ }^{9,10}$

Clinical practice guidelines (CPGs) are systematically developed statements that are meant to inform decisionmaking regarding specific clinical situations. ${ }^{11,12}$ They have the ability to improve the quality and consistency of care provided by bridging the gap between clinicians' knowledge/practices and what is supported in the literature. ${ }^{12,13}$ Ideally, CPGs should analyze and distil the best evidence to provide direction to health care providers. However, guidelines may contain flawed or inaccurate content, may be presented in a suboptimal fashion, or may be poorly generalizable to individual patients. ${ }^{12,13}$ Other barriers to implementation include clinician factors such as lack of agreement with published guidelines or limited time and resources, or patient factors such as specific preferences and expectations. ${ }^{14}$

The Appraisal of Guidelines for Research \& Evaluation II instrument (AGREE-II) is a standardized and validated tool used to evaluate the quality and methodology of CPGs. ${ }^{15,16} \mathrm{It}$ is considered by many to be the gold standard for guideline appraisal..$^{17,18}$

Given the potential variation in practice patterns among Canadian surgeons, our objective was to examine Canadian rectal cancer CPGs to evaluate their quality, developmental methodology, presentation and interprovincial concordance.

\section{Methods}

We obtained CPGs from the websites and/or publications of the responsible organization within each province and territory. ${ }^{19-31}$ These included the British Columbia Cancer Agency, Alberta Health Services, Saskatchewan Cancer Agency, Cancer Care Manitoba, Cancer Care Ontario, Institut national d'excellence en santé et en services sociaux and Groupe d'étude en oncologie du Québec, and Cancer Care Nova Scotia. The latest published guidelines from each organization were used for this study; these were separate from care pathways or care maps published by the same organizations. From these guidelines, 2 of us (Z.M.M. and D.Y.) independently extracted information regarding stage I, II and III (i.e., curable) rectal cancers. Accuracy of extracted information was verified by a third, independent assessor (S.V.P.).

Recommendations for diagnostic and staging work-up (locoregional staging, assessment for distant metastases), treatment by stage (neoadjuvant therapy, surgery, adjuvant therapy) and protocols for post-treatment surveillance (endoscopic evaluation, imaging, tumour marker assessment, clinical visits) were assessed.

Each English guideline was evaluated and scored independently by 2 reviewers (Z.M.M. and D.Y.) for quality using the Appraisal of Guidelines for Research \& Evaluation II (AGREE-II) instrument. The domains of evaluation included scope and purpose, stakeholder involvement, rigour of development, clarity of presentation, applicability, and editorial independence. In addition to these, there are 2 global rating items within the assessment that rate the overall quality of each guideline and whether they would be recommended for use; however, we chose not to make a recommendation for or against the use of each CPG. Scaled domain scores for each guideline were then calculated as per AGREE-II methodology; within each domain, a score from 1 to 7 was assigned by each reviewer. A score of 1 reflects either no information or poor reporting of an AGREE II item/ concept. Conversely, a score of 7 indicates exceptional reporting of an AGREE II item/concept. Each pair of scores was summed, and the total was scaled as a percentage of the maximum possible score for that domain. A Spearman rank correlation coefficient was calculated to determine interrater agreement.

It should be noted that the AGREE-II process does not have a set minimum domain score to delineate the difference between a guideline that is considered to be of higher quality versus one considered to be of lower quality; such decisions are subjective and left to the user of the instrument.

\section{REsults}

We obtained CPGs specific to rectal cancer management from 7 of the 13 Canadian provinces and territories (Table 1). Most were available as published documents, but the $\mathrm{BC}$ guidelines were published online only. Guidelines from New Brunswick, Newfoundland \& Labrador, Prince Edward Island, Nunavut, Yukon, and the Northwest Territories were not available, despite our attempts to obtain them. The CPGs varied with respect to year of most recent update(s). 


\section{Guideline evaluation using AGREE-II}

All English guidelines were rated across different domains using the AGREE-II instrument (Table 2 and Fig. 1). Guidelines from Manitoba, Ontario and Nova Scotia scored well; average domain scores were above $50 \%$. Conversely, guidelines from Saskatchewan and British Columbia scored the lowest; their average domain scores were below $20 \%$. The majority of differences were noted within the domains of applicability and rigour of development, as defined by the AGREE-II instrument. The Spearman rank correlation coefficient was 0.90 , indicating a statistically significant agreement of domain scores between the 2 assessors.

\section{Diagnosis and staging work-up}

All 7 guidelines recommended measuring carcinoembryonic antigen (CEA) levels, complete colonoscopy (if possible), and computed tomographcy (CT) of the abdomen and pelvis as part of the initial staging work-up for rectal cancer. The primary difference was noted in the use of magnetic resonance imaging (MRI) versus endorectal ultrasound (ERUS) for local staging of tumours. Guidelines from British Columbia and

\begin{tabular}{|c|c|c|}
\hline Province/territory & Availability & Year(s) of publication \\
\hline British Columbia & Yes & 2012 \\
\hline Alberta & Yes & 2013, 2014, 2017 \\
\hline Saskatchewan & Yes & 2011,2013 \\
\hline Manitoba & Yes & 2014, 2015, 2018 \\
\hline Ontario & Yes & $2013,2014,2016$ \\
\hline Quebec & Yes & 2016 \\
\hline Nova Scotia & Yes & 2016 \\
\hline Newfoundland \& Labrador & No & - \\
\hline New Brunswick & No & - \\
\hline Prince Edward Island & No & - \\
\hline Nunavut & No & - \\
\hline Northwest Territories & No & - \\
\hline Yukon & No & - \\
\hline
\end{tabular}

Saskatchewan did not indicate a strong preference for either MRI or ERUS, whereas guidelines from Alberta, Ontario, Quebec and Nova Scotia recommended MRI (Table 3). Ontario and Manitoba guidelines provided specific scenarios for the use of MRI and ERUS in staging. In addition, while the majority of guidelines suggested CT to stage the chest, the BC guidelines recommended chest radiography over CT, and the Manitoba guidelines did not declare a preference (Table 3).

\section{Neoadjuvant recommendations by stage}

Guidelines frrom British Columbia, Alberta, Manitoba, Ontario and Nova Scotia did not recommend neoadjuvant therapy for stage I rectal cancer (Table 4); however, guidelines from Saskatchewan and Quebec suggested neoadjuvant therapy in the setting of select T2N0 and low tumours to obtain better opportunities for sphincter preservation at the time of surgery. All guidelines recommended neoadjuvant therapy for stage II and III rectal cancers, but their recommendations differed for shortcourse radiotherapy versus long-course chemoradiotherapy as the protocol of choice (Table 4). Guidelines from Saskatchewan, Ontario and Nova Scotia recommended long-course neoadjuvant treatment, whereas the guideline from Manitoba recommended short-course. British Columbia recommended long-course for patients with fixed tumours, predicted positive circumferential margins, and distal rectal cancers versus short-course for nonfixed and middle/proximal rectal cancers. Alberta recommended long-course for patients "not amenable to resection." Overall, the neoadjuvant protocols themselves were fairly consistent (data not shown).

\section{Surgery recommendations by stage}

Surgical resection was recommended as the primary curative option for stage I rectal cancer in all of the guidelines. Transanal excision (TAE) in stage I disease was mentioned in most guidelines (British Columbia, Alberta, Quebec, Nova Scotia), whereas

Table 2. Guideline evaluation using AGREE-II domain scores

\begin{tabular}{|c|c|c|c|c|c|c|}
\hline AGREE II Domain & \multicolumn{6}{|c|}{ Province, score } \\
\hline Scope \& purpose & $0 \%$ & $86 \%$ & $17 \%$ & $100 \%$ & $94 \%$ & $50 \%$ \\
\hline Rigour of development & $0 \%$ & $19 \%$ & $1 \%$ & $86 \%$ & $50 \%$ & $30 \%$ \\
\hline Clarity of presentation & $81 \%$ & $53 \%$ & $56 \%$ & $94 \%$ & $94 \%$ & $92 \%$ \\
\hline Applicability & $0 \%$ & $0 \%$ & $0 \%$ & $65 \%$ & $52 \%$ & $42 \%$ \\
\hline Average domain score & $15 \%$ & $43 \%$ & $13 \%$ & $84 \%$ & $71 \%$ & $52 \%$ \\
\hline
\end{tabular}



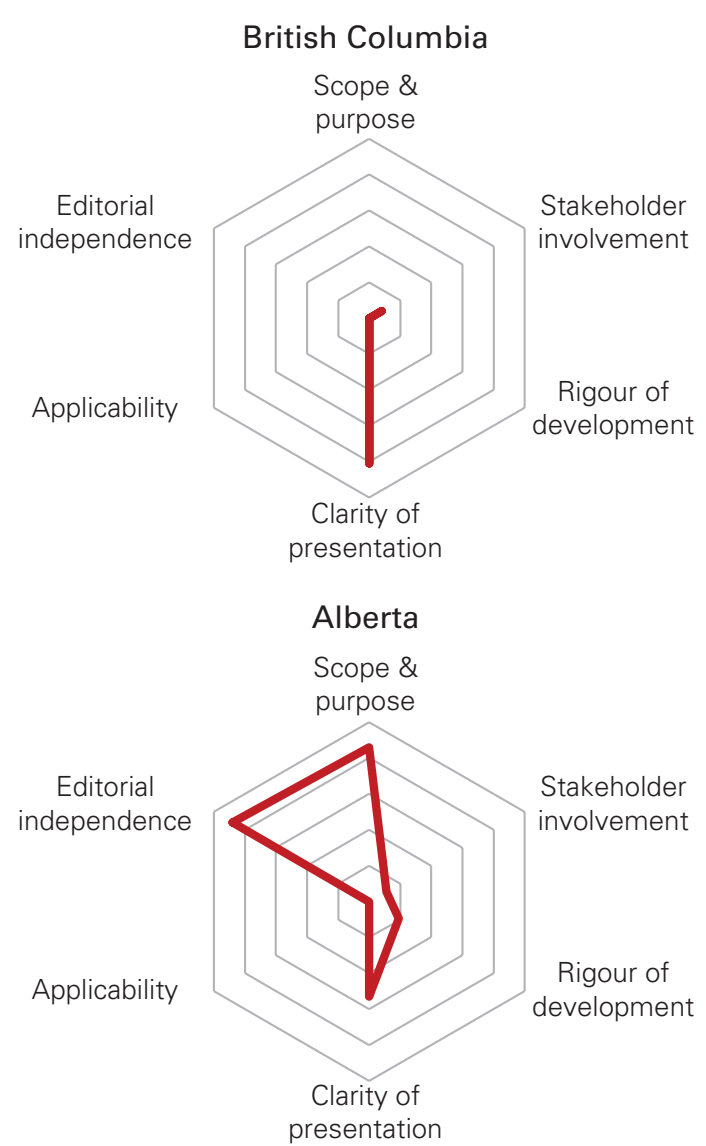

Ontario

Scope \&

purpose

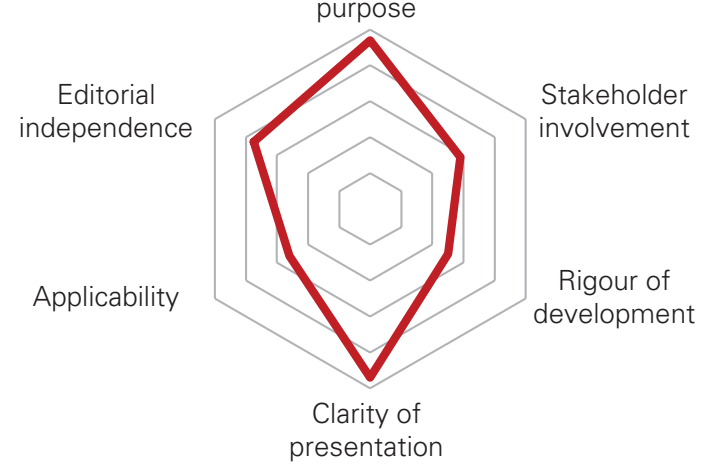

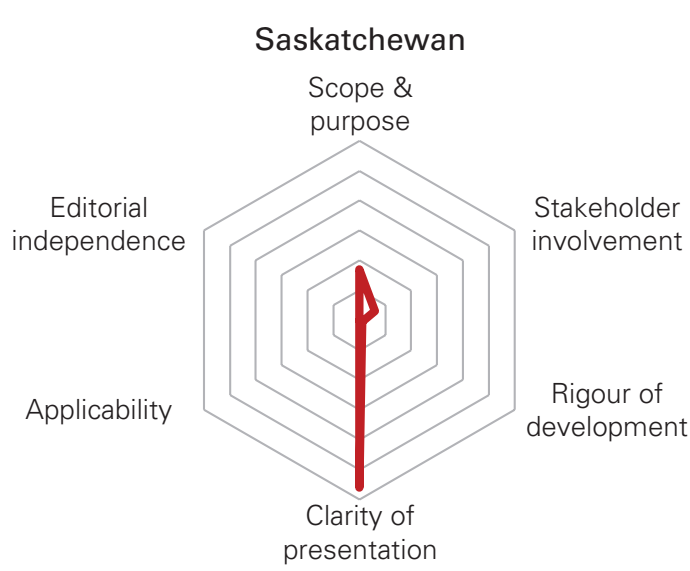
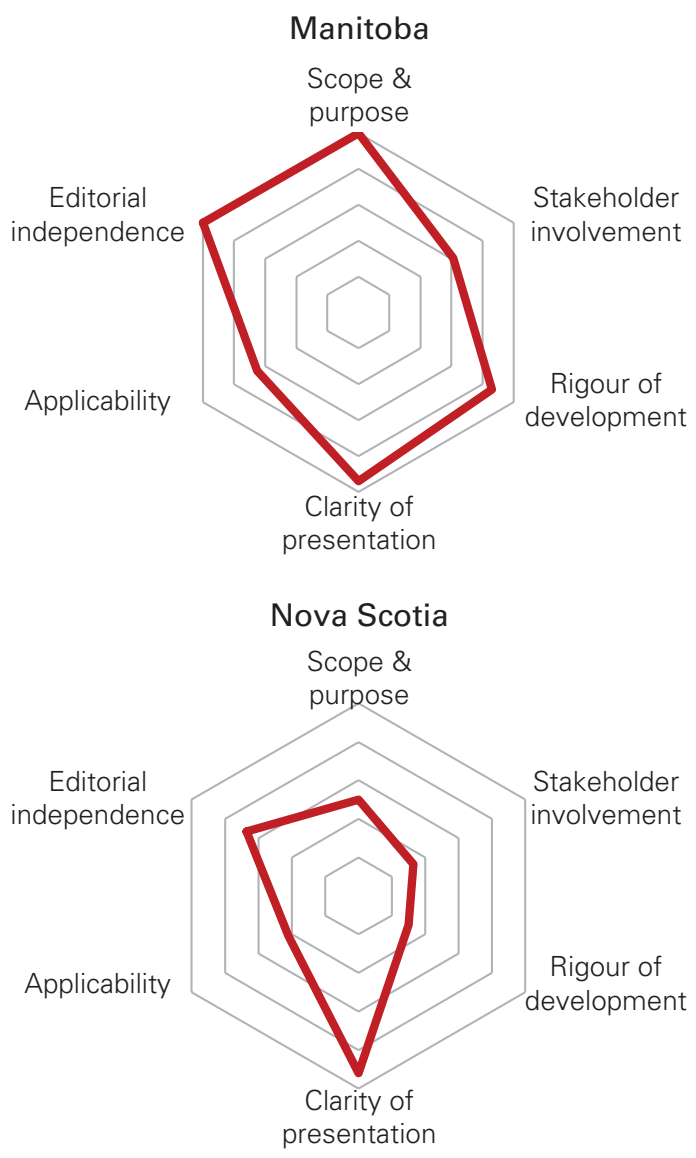

Fig. 1. Appraisal of Guidelines for Research \& Evaluation II instrument (AGREE-II) domain scores of each provincial guideline.

Manitoba and Ontario guidelines did not comment specifically on TAE (Table 5). Specific considerations for TAE eligibility include node-negative cancers, absence of lymphovascular or perineural invasion, and tumour size $<3 \mathrm{~cm}$. The guideline from Saskatchewan did not discuss surgical technique in any great detail.
For stage II and III disease, surgical recommendations were within the context of neoadjuvant protocols, and radical resection was recommended with a focus on total mesorectal excision (TME). The time between completion of neoadjuvant therapy and surgery was similar in all assessed guidelines (i.e., time from short-course to surgery 7-10 days; time from long-course to surgery 4-6 weeks or 6-10 weeks). 


\begin{tabular}{|c|c|c|c|}
\hline Province & MRI v. ERUS & $\begin{array}{l}\text { Abdominal } \\
\text { staging }\end{array}$ & $\begin{array}{l}\text { Chest } \\
\text { staging }\end{array}$ \\
\hline British Columbia & No preference & $\begin{array}{l}\text { CT abdomen/ } \\
\text { pelvis }\end{array}$ & $\begin{array}{c}\text { CXR } \\
\text { preferred }\end{array}$ \\
\hline Alberta & $\begin{array}{l}\text { MRI preferred } \\
\text { (especially if SC } \\
\text { planned) }\end{array}$ & $\begin{array}{l}\text { CT abdomen/ } \\
\text { pelvis }\end{array}$ & $\begin{array}{c}\mathrm{CT} \\
\text { preferred }\end{array}$ \\
\hline Saskatchewan & No preference & $\begin{array}{l}\text { CT abdomen/ } \\
\text { pelvis }\end{array}$ & $\begin{array}{c}\mathrm{CT} \\
\text { preferred }\end{array}$ \\
\hline Manitoba & $\begin{array}{l}\text { ERUS preferred } \\
\text { (especially for } \\
\text { small or low } \\
\text { tumours) } \\
\text { MRI for all stenotic } \\
\text { tumours }\end{array}$ & $\begin{array}{l}\text { CT abdomen/ } \\
\text { pelvis }\end{array}$ & CXR or CT \\
\hline Ontario & $\begin{array}{l}\text { MRI preferred } \\
\text { ERUS for low } \\
\text { tumours }\end{array}$ & $\begin{array}{l}\text { CT abdomen/ } \\
\text { pelvis }\end{array}$ & $\begin{array}{c}\mathrm{CT} \\
\text { preferred }\end{array}$ \\
\hline Quebec & MRI preferred & $\begin{array}{l}\text { CT abdomen/ } \\
\text { pelvis }\end{array}$ & $\begin{array}{c}\mathrm{CT} \\
\text { preferred }\end{array}$ \\
\hline Nova Scotia & MRI preferred & $\begin{array}{l}\text { CT abdomen/ } \\
\text { pelvis }\end{array}$ & $\begin{array}{c}\mathrm{CT} \\
\text { preferred }\end{array}$ \\
\hline $\begin{array}{l}\mathrm{CT}=\text { computed to } \\
\mathrm{MRI}=\text { magnetic } \mathrm{re}\end{array}$ & $\begin{array}{l}\text { hy; } C X R=\text { chest rad } \\
\text { ce imaging; } S C=\text { sh }\end{array}$ & $\begin{array}{l}\text { y; ERUS = endor } \\
\text { se radiotherapy of }\end{array}$ & ultrasound; \\
\hline
\end{tabular}

\begin{tabular}{|c|c|c|}
\hline Province & Stage I & Stage II \& III \\
\hline British Columbia & - & $\begin{array}{l}\text { SC for non-fixed, upper } 2 / 3 \\
\text { location } \\
\text { LC for fixed or predicted +CRM }\end{array}$ \\
\hline Alberta & - & $\begin{array}{l}\text { SC for "amenable to resection" } \\
\text { LC preferred for stage II/III, and if } \\
\text { "not amenable to resection" }\end{array}$ \\
\hline Saskatchewan & $\begin{array}{l}\text { Chemoradiation } \\
\text { for select T2NO } \\
\text { and low tumours }\end{array}$ & LC standard \\
\hline Manitoba & - & $\begin{array}{c}\text { SC preferred } \\
\text { LC for down-staging, sphincter } \\
\text { preservation }\end{array}$ \\
\hline Ontario & - & LC Preferred \\
\hline Quebec & $\begin{array}{l}\text { For sphincter } \\
\text { preservation }\end{array}$ & $\begin{array}{l}\text { No specific preference but states } \\
\text { that majority of clinicians use LC }\end{array}$ \\
\hline Nova Scotia & - & LC preferred \\
\hline
\end{tabular}

\section{Adjuvant protocols by stage}

Adjuvant systemic therapy was not recommended for stage I rectal cancer in any of the CPGs. Manitoba, Ontario and Quebec guidelines did discuss adjuvant therapy for stage I disease if there was pathological upstaging postresection (Table 6). The $\mathrm{BC}$ guideline recommended adjuvant radiotherapy if local excision was carried out.

For stage II and III disease, all guidelines recommended some form of adjuvant systemic therapy,
Table 5. Surgical treatment recommendations, by stage

\begin{tabular}{|lcc|}
\hline Province & Stage I & \multicolumn{1}{c}{ Stage II \& III } \\
\hline British Columbia & TAE offered & $\begin{array}{c}\text { For SC, surgery within 10 d } \\
\text { For LC, surgery within 6-10 wk }\end{array}$ \\
\hline Alberta & TAE offered & $\begin{array}{c}\text { For SC, surgery within 1 wk } \\
\text { For LC, surgery within 6-8 wk }\end{array}$ \\
\hline Saskatchewan & No details & $\begin{array}{c}\text { For SC, surgery within 7-10 d } \\
\text { For LC, surgery within 6-8 wk }\end{array}$ \\
\hline Manitoba & $\begin{array}{c}\text { Highlights } \\
\text { importance of } \\
\text { TME technique }\end{array}$ & $\begin{array}{c}\text { For SC, "immediate" surgery } \\
\text { For LC, surgery within 6-8 wk }\end{array}$ \\
\hline Ontario & $\begin{array}{c}\text { Highlights } \\
\text { importance of } \\
\text { TME technique }\end{array}$ & $\begin{array}{c}\text { For SC, surgery within 10 d } \\
\text { For LC, surgery within 4-6 wk }\end{array}$ \\
\hline Quebec & TAE offered & $\begin{array}{c}\text { For SC, "immediate" surgery } \\
\text { For LC, does not specify time to } \\
\text { surgery }\end{array}$ \\
\hline Nova Scotia & TAE offered & $\begin{array}{c}\text { For SC, surgery within 10 d } \\
\text { For LC, surgery within 6-10 wk }\end{array}$ \\
\hline $\begin{array}{l}\text { LC = long-course chemoradiotherapy; SC = short-course radiotherapy only; TAE = } \\
\text { transanal excision; TME = total mesorectal excision. }\end{array}$
\end{tabular}

Table 6. Adjuvant treatment recommendations, by stage

\begin{tabular}{|c|c|c|}
\hline Province & Stage I & Stage II \& III \\
\hline British Columbia & $\begin{array}{l}\text { Radiotherapy } \\
\text { if LE }\end{array}$ & $\begin{array}{c}\text { Capecitabine } \times 6 \text { mo post-SC } \\
\text { Capecitabine } \times 4 \text { mo post-LC } \\
\text { For stage III disease, mFOLFOX6 may } \\
\text { be considered, especially if } \mathrm{N}+\end{array}$ \\
\hline Alberta & - & $\begin{array}{l}6 \text { mo of adjuvant therapy recommended } \\
\text { for stage II with "high-risk features" } \\
\text { and all stage III (CAPOX/XELOX, } \\
\text { mFOLFOX6, or capecitabine)* }\end{array}$ \\
\hline Saskatchewan & - & $\begin{array}{c}\text { Capecitabine, 5-FU, mFOLFOX, or } \\
\text { CapeOX } \times 6 \text { mo }\end{array}$ \\
\hline Manitoba & If upstaged & $\begin{array}{l}\text { Fluoropyrimidine-based therapy offered } \\
\text { postoperatively }\end{array}$ \\
\hline Ontario & If upstaged & $\begin{array}{l}\text { No adjuvant therapy if upstaged to II/III } \\
\text { Fluoropyrimidine-based therapy, } \\
\text { post-op Oxaliplatin-based therapy, or } \\
\text { capecitabine for high risk of systemic } \\
\text { recurrence }\end{array}$ \\
\hline Quebec & If upstaged & $\begin{array}{l}\text { 5FU/LV or FOLFOX for } 8-12 \text { cycles } \\
\text { (FOLFOX preferred if upstaged) }\end{array}$ \\
\hline Nova Scotia & - & $\begin{array}{l}\text { 5FU or capecitabine; FOLFOX if high } \\
\text { risk of recurrence }\end{array}$ \\
\hline \multicolumn{3}{|c|}{$\begin{array}{l}\mathrm{LC}=\text { long-course chemoradiotherapy; } \mathrm{LE}=\text { local excision; } \mathrm{SC}=\text { short-course radiotherapy } \\
\text { only. } \\
\text { *Extrapolated from colon cancer. }\end{array}$} \\
\hline
\end{tabular}

although there was variability in recommendations among the guidelines (Table 6). Adjuvant radiotherapy was not routinely recommended in any CPG.

\section{Post-treatment surveillance recommendations}

Post-treatment surveillance for stage I disease was limited to routine screening colonoscopy in all provinces. For stage II/III disease, surveillance included routine clinical visits, CEA testing, abdomen/pelvic imaging and 


\begin{tabular}{|c|c|c|c|c|}
\hline Province & History/physical & CEA & CT abdomen/pelvis & Colonoscopy \\
\hline British Columbia & $\begin{array}{l}\text { Every 3-6 mo for } 3 \mathrm{yr} \\
\text { Every } 6 \mathrm{mo} \text { for } 2 \mathrm{yr}\end{array}$ & At each visit & Annually for $3 \mathrm{yr}$ & $\begin{array}{l}\text { At } 1 \& 4 \text { yr post-op } \\
\text { Every } 5 \text { yr thereafter }\end{array}$ \\
\hline Alberta & Not specified & Every $3 \mathrm{mo}$ for $3 \mathrm{yr}$ & $\begin{array}{l}\text { Annually for } 2 \text { yr } \\
\text { ( } \pm \text { third year) }\end{array}$ & $\begin{array}{l}\text { At } 1 \& 4 \text { yr post-op } \\
\text { Every } 5 \text { yr thereafter }\end{array}$ \\
\hline Saskatchewan & $\begin{array}{l}\text { Every } 3-6 \text { mo for } 3 \text { yr } \\
\text { Every 6-12 mo for } 2 \text { yr } \\
\text { Annually thereafter }\end{array}$ & $\begin{array}{l}\text { Every } 3-6 \text { mo for } 3 \mathrm{yr} \\
\text { Every } 6-12 \mathrm{mo} \text { for } 2 \mathrm{yr}\end{array}$ & Annually for $3 \mathrm{yr}$ & $\begin{array}{c}\text { At } 1 \text { yr post-op } \\
\text { If no polyps, every } 3-5 \text { yr thereafter } \\
\text { Flexible proctosigmoidoscopy ever } 6 \text { mo for } 5 \text { yr* }\end{array}$ \\
\hline Manitoba & $\begin{array}{l}\text { Every } 3 \mathrm{mo} \text { for } 3 \mathrm{yr} \\
\text { Every } 6 \mathrm{mo} \text { for } 2 \mathrm{yr}\end{array}$ & Every 3 mo for 3 yr & Annually for $3 \mathrm{yr}$ & $\begin{array}{c}\text { At } 1 \text { \& } 3 \text { yr post-op } \\
\text { Every } 5 \text { yr thereafter } \\
\text { Flexible sigmoidoscopy every } 6 \text { mo for } 3 \text { yr post-op* }\end{array}$ \\
\hline Ontario & Every $6 \mathrm{mo}$ for $5 \mathrm{yr}$ & At each visit & Annually for $3 \mathrm{yr}$ & $\begin{array}{c}\text { At } 1 \text { yr post-op } \\
\text { Every } 5 \text { yr thereafter } \\
\text { Rectosigmoidoscopy every } 6 \text { mo for } 2-5 \text { yr post-op* }\end{array}$ \\
\hline Quebec & $\begin{array}{l}\text { Every 3-6 mo for } 3 \text { yr } \\
\text { Annually thereafter }\end{array}$ & At each visit & Annually for 3 yr & $\begin{array}{c}\text { At } 1 \text { yr post-op } \\
\text { If no polyps, every } 3-5 \mathrm{yr} \text { thereafter }\end{array}$ \\
\hline Nova Scotia & $\begin{array}{l}\text { Every } 3 \mathrm{mo} \text { for } 3 \mathrm{yr} \\
\text { Every } 6 \mathrm{mo} \text { for } 2 \mathrm{yr}\end{array}$ & At each visit & Annually for $3 \mathrm{yr}$ & $\begin{array}{c}\text { At } 1 \text { yr post-op } \\
\text { No specific surveillance recommendation thereafter } \\
\text { Rigid or flexible sigmoidoscopy at } 6,18,24 \text { and } 36 \text { mo } \\
\text { post-op }\end{array}$ \\
\hline
\end{tabular}

colonoscopy. The various recommendations by province are shown in Table 7. While we noted minor differences across most of these domains among the guidelines, the main variation existed in evaluation of the colon and rectum. Only 4 of the guidelines (Saskatchewan, Manitoba, Ontario, Nova Scotia) explicitly advised clinicians to perform proctosigmoidoscopy postoperatively, in addition to colonoscopies, to assess anastomoses. The duration of endoscopic surveillance postoperatively also differed among guidelines.

\section{Discussion}

The management of rectal cancer is a complex and evolving area that relies on accurate diagnosis, staging and multidisciplinary treatment for optimal patient outcomes. Clinical practice guidelines play an important role in synthesizing the latest literature and subsequently disseminating evidence-based recommendations to clinicians. We present the assessment and comparison of Canadian provincial CPGs for the management of rectal cancer. Of the 13 provinces and territories, we obtained and analyzed 7 guidelines (British Columbia, Alberta, Saskatchewan, Manitoba, Ontario, Quebec, Nova Scotia); guidelines from the remaining provinces/ territories were not readily available. We noted that available CPGs were not all current and had been updated at variable intervals. Using the validated AGREE-II instrument for guideline evaluation, we noted varying quality, developmental methodology and presentation among the CPGs. In addition, there was notable interprovincial variation in clinical recommendations. These differences were within the areas of imaging for locoregional staging, assessment for pulmonary metastases, neoadjuvant therapy protocols (short-course v. long-course), recommendations for transanal excision, adjuvant therapy indications and protocols, and post-treatment surveillance algorithms.

While recent work has shown significant variation in recommendations between North American, European, and Japanese rectal cancer guidelines, it focused on describing the differences without an actual appraisal of each CPG. ${ }^{39}$ To our knowledge, our study is the first such evaluation of rectal cancer CPGs in Canada, and we provide an objective comparison as well as an appraisal of the recommendations within these guidelines. While we endeavour to highlight the differences between these CPGs as well as the scientific standards surrounding their development, the evaluation of the actual clinical content within them is outside of the scope of this study. Nonetheless, the strengths of our study lie in its comprehensive examination of national CPGs, thereby providing useful feedback for stakeholders involved in guideline development to consider as they update, improve and disseminate their recommendations.

From a pragmatic standpoint, an important question is whether there are differences in the care received by patients with rectal cancer. Previous Canadian studies have highlighted self-reported differences in practice patterns among rectal cancer surgeons through the use 
of national and provincial surveys, suggesting that this may be the case..$^{910,32}$ These differences are attributed to factors such as level of training (i.e., subspecialty v. nonfellowship), participation in continuing professional development, length of time in practice, location of practice, and access to clinical resources (e.g., MRI, ERUS). Whether or not these self-reported differences in practice patterns translate to variability in patient-level outcomes is unclear at this time. It is possible that differences in CPGs may contribute at least in part to variations in clinical practice, but there are likely multiple causative factors.

Unlike variation among surgeons and clinicians, it is harder to discern specific factors contributing to the variation among CPGs. Certainly, the resources available to each provincial/territorial cancer agency as well as the volume and size of institutions within each province dictate the amount of time and expertise that can be devoted toward the development of CPGs. ${ }^{12,13}$ As a result, we assume recommendations are made taking each province's respective health care context (i.e., health care funding, clinical volume, technology, number of specialists) into account.

Another consideration relates to the body of evidence on which CPGs are based. In the context of rectal cancer, this is best illustrated by recommendations for neoadjuvant therapy. Owing to the amount of ongoing research comparing and evaluating neoadjuvant chemoradiotherapy protocols (e.g., short-course, delayed short-course, long course), recommendations continue to evolve, and certainly there remains equipoise in this area. ${ }^{5,733-35}$ This is reflected in the guidelines we examined, which differed in their endorsement of specific neoadjuvant protocols, as there is no definitive evidence yet for clinical practice.

When trying to reconcile the observed variations across Canada in clinical practice guidelines and selfreported practice patterns for rectal cancer, what ultimately matters most is whether these translate into worse outcomes for patients. If yes, then philosophically this highlights the notion of acceptable and unacceptable variations in clinical practice. When there is uncertainty in the literature about a particular intervention, then variations in recommendations and practice are expected and may be acceptable as long as the care is competent. ${ }^{36}$ Conversely, if there is no equipoise, or if there is a lack of consistency due to modifiable provider and system factors, then we may consider differences in clinical guidelines and practice patterns to be unacceptable. From our study, the majority of variability in CPGs reflected areas with either limited or evolving evidence. Explaining the relationship between CPG variability and outcomes in patients with rectal cancer is beyond the scope of our investigation, and is also a complex relationship to disentangle.

\section{Limitations}

Our study is not without limitations; some of these relate to our use of the AGREE-II instrument for guideline evaluation. Despite being a validated and frequently used tool for guideline appraisal, the instrument does not provide a context for interpreting the scaled domain scores of a guideline. ${ }^{16,37,38}$ Therefore, once domain scores have been determined, the evaluator must interpret these scores on their own when considering whether or not to recommend a guideline for use. While it stands to reason that higher domain scores suggest higher-quality guidelines, this lack of context introduces an element of subjectivity into the entire appraisal process. For this reason, we felt compelled to present only the scaled domain scores for each guideline rather than subjectively assess whether or not we would recommend them for use.

\section{CONCLUSION}

We found that rectal cancer CPGs in Canada vary in their presentation style, content, quality and recency. We know from previous studies that self-reported practice patterns within this area already vary among Canadian surgeons, and given the rapidly evolving evidence surrounding rectal cancer management, CPGs can serve to provide vetted and clear recommendations for clinicians to follow. Thus, there may be a role for uniform CPGs in the management of rectal cancer, and further research is necessary to determine if and how this might affect patient outcomes.

Affiliations: From the Department of Surgery, Queen's University, Kingston Health Sciences Centre, Kingston, Ont. (Mir, Yu, Merchant, Patel); and the Department of Oncology, Queen's University, Kingston, Ont. (Booth).

Competing interests: None declared.

Contributors: Z. Mir and S. Patel designed the study. Z. Mir, D. Yu and S. Patel acquired the data, which all authors analyzed. Z. Mir, D. $\mathrm{Yu}$ and S. Patel wrote the article, which all authors reviewed and approved for publication.

\section{References}

1. Canadian Cancer Society's Advisory Committee on Cancer Statistics. Canadian Cancer Statistics 2017. Toronto (ON): Canadian Cancer Society; 2017. Available: cancer.ca/Canadian-Cancer-Statistics2017-EN.pdf (accessed 2018 Nov. 13).

2. São Julião GP, Habr-Gama A, Vailati BB, et al. New strategies in rectal cancer. Surg Clin North Am 2017;97:587-604.

3. Plummer JM, Leake P-A, Albert MR. Recent advances in the management of rectal cancer: no surgery, minimal surgery or minimally invasive surgery. World 7 Gastrointest Surg 2017;9:139-48.

4. Kosinski L, Habr-Gama A, Ludwig K, et al. Shifting concepts in rectal cancer management: a review of contemporary primary rectal cancer treatment strategies. CA Cancer F Clin 2012;62:173-202.

5. Díaz Beveridge R, Akhoundova D, Bruixola G, et al. Controversies in the multimodality management of locally advanced rectal cancer. Med Oncol 2017;34:102. 
6. Artac M, Korkmaz L, El-Rayes B, et al. An update on the multimodality of localized rectal cancer. Crit Rev Oncol Hematol 2016;108:23-32.

7. Lee L, Kelly J, Nassif GJ, et al. Chemoradiation and local excision for $\mathrm{T} 2 \mathrm{~N} 0$ rectal cancer offers equivalent overall survival compared to standard resection: a National Cancer Database analysis. 7 Gastrointest Surg 2017;21:1666-74.

8. Wiltink LM, Nout RA, van der Voort van Zyp JRN, et al. Longterm health-related quality of life in patients with rectal cancer after preoperative short-course and long-course (chemo) radiotherapy. Clin Colorectal Cancer 2016;15:e93-9.

9. Chuah TK, Lee T, Wirtzfeld D, et al. Management of primary rectal cancer by surgeons in Atlantic Canada: results of a regional survey. Can 7 Surg 2010;53:396-402.

10. Richardson DP, Porter GA, Johnson PM. Self-reported practice patterns and knowledge of rectal cancer care among Canadian general surgeons. Can F Surg 2014;57:385-90.

11. Institute of Medicine (US) Committee to Advise the Public Health Service on Clinical Practice Guidelines. Clinical Practice Guidelines: Directions for a New Program. Washington (DC): National Academies Press (US); 1990.

12. Woolf SH, Grol R, Hutchinson A, et al. Potential benefits, limitations, and harms of clinical guidelines. BMF 1999;318:527-30.

13. Dean Boudoulas K, Leier CV, Geleris P, et al. The shortcomings of clinical practice guidelines. Cardiology 2015;130:187-200.

14. Cabana MD, Rand CS, Powe NR, et al. Why don't physicians follow clinical practiec guidelines? A framework for improvement. $7 A M A$ 1999;282:1458-65.

15. The AGREE Collaboration. Development and validation of an international appraisal instrument for assessing the quality of clinical practice guidelines: the AGREE project. Qual Saf Health Care 2003;12:18-23.

16. Brouwers MC, Kho ME, Browman GP, et al. AGREE II: advancing guideline development, reporting and evaluation in health care. CMA7 2010;182:E839-42.

17. Abdelsattar ZM, Reames BN, Regenbogen SE, et al. Critical evaluation of the scientific content in clinical practice guidelines. Cancer 2015;121:783-9.

18. Eccles MP, Grimshaw JM. Selecting, presenting and delivering clinical guidelines: Are there any "magic bullets"? Med 7 Aust 2004; 180(Suppl):S52-4.

19. Saskatchewan Cancer Agency. Provincial Colorectal Cancer Treatment Guidelines. 2011. Available: http://www.saskcancer.ca/Colorectal CPGs (accessed 2018 Nov. 13).

20. Institut national d'excellence en santé et en services sociaux (INESSS) et Groupe d'étude en oncologie du Québec (GEDQ). Algorithmes d'investigation, de traitement et de suivi cancer du rectum. 2016. Available: www.tncd.org (accessed 2018 Nov. 13).

21. Cancer Care Ontario. Rectal Cancer Treatment Pathway (version 2018.03). 2018. Available: https://www.cancercareontario.ca/en/ pathway-maps/colorectal-cancer (accessed 2018 Nov. 13).

22. Members of the Colorectal Cancer Survivorship Group. Follow-up care, surveillance protocol, and secondary prevention measures for survivors of colorectal cancer. Program in Evidence-based Care Evidence-Based Series No.: 26-2 Version 2. Toronto (ON): Cancer Care Ontario; 2012.

23. Wong RKS, Berry S, Spithoff K, et al.; Gastrointestinal Cancer Disease Site Group. Preoperative or postoperative therapy for stage II or III rectal cancer: an updated practice guideline. Clin Oncol $(R$ Coll Radiol) 2010;22:265-71.
24. Smith AJ, Driman DK, Spithoff K, et al.; Expert Panel on Colon and Rectal Cancer Surgery and Pathology. Guideline for optimization of colorectal cancer surgery and pathology. 7 Surg Oncol 2010;101:5-12.

25. Kennedy E, Vella ET, MacDonald DB, et al. Optimisation of preoperative assessment in patients diagnosed with rectal cancer. Clin Oncol 2015;27:225-45.

26. Cancer Care Nova Scotia. Clinical Standards Oversight Committee. Clinical Standards for the Treatment of Rectal Cancer in Nova Scotia. 2016. Available: http://www.cdha.nshealth.ca/nova-scotia-cancer -care-program-3 (accessed 2018 Nov. 13).

27. Cancer Care Manitoba. Colorectal Cancer Patient Follow-up Treatment Summary and Follow-up Schedule Form. 2018. Available: https:// www.cancercare.mb.ca/For-Health-Professionals/follow-up-care -resources (accessed 2018 Nov. 13).

28. Cancer Care Manitoba. Disease Management. Provincial Consensus on Diagnostic and Treatment Recommendations for the Management of Rectal Cancer. 2015. Available: https://www.cancercare.mb.ca/For -Health-Professionals/treatment-guidelines-regimen-reference -orders (accessed 2018 Nov. 13).

29. Cancer Care Manitoba. Timeline Model in Manitoba for the Colon or Rectal Cancer Patient Fourney from Suspicion of Cancer to Treatment in Sixty Days. 2014. Available from: https://www.cancercare.mb.ca/ For-Health-Professionals/diagnostic-pathway-for-suspected-cancer -and-blood-disorders (accessed 2018 Nov. 13).

30. Alberta Provincial Gastrointestinal Tumor Team. Early stage rectal cancer: Clinical Practice Guideline GI-005, Version 4. 2013. Available from: http://www.albertahealthservices.ca/assets/info/hp/cancer/if-hp -cancer-guide-gi005-early-stage-rectal.pdf (accessed 2018 Nov. 13).

31. Alberta Provincial Gastrointestinal Tumor Team. Stages II and III Colorectal Cancer Surveillance Clinical Practice Guideline GI-002, Version 6. 2014. Available from: http://www.albertahealthservices.ca/hp/if-hp -cancer-guide-gi002-colon-surveillance.pdf (accessed 2018 Nov. 13).

32. McMullen TP, Easson AM, Cohen Z, et al. The investigation of primary rectal cancer by surgeons: current pattern of practice. Can $\mathcal{F}$ Surg 2005;48:19-26.

33. Erlandsson J, Holm T, Pettersson D, et al. Optimal fractionation of preoperative radiotherapy and timing to surgery for rectal cancer (Stockholm III): a multicentre, randomised, non-blinded, phase 3, non-inferiority trial. Lancet Oncol 2017;18:336-46.

34. Latkauskas T, Pauzas H, Gineikiene I, et al. Initial results of a randomized controlled trial comparing clinical and pathological downstaging of rectal cancer after preoperative short-course radiotherapy or long-term chemoradiotherapy, both with delayed surgery. Colorectal Dis 2012;14:294-8.

35. Ansari N, Solomon MJ, Fisher RJ, et al. Acute adverse events and postoperative complications in a randomized trial of preoperative short-course radiotherapy versus long-course chemoradiotherapy for T3 adenocarcinoma of the rectum: Trans-Tasman Radiation Oncology Group trial (TROG 01.04). Ann Surg 2017;265:882-8.

36. Weijer C, Miller PB. When are research risks reasonable in relation to anticipated benefits? Nat Med 2004;10:570-3

37. Polus S, Lerberg P, Vogel J, et al. Appraisal of WHO guidelines in maternal health using the AGREE II assessment tool. PLoS One 2012;7:8-12

38. Hoffmann-Eßer W, Siering U, Neugebauer EAM, et al. Guideline appraisal with AGREE II: systematic review of the current evidence on how users handle the 2 overall assessments. PLoS One 2017;12:1-15.

39. Luzietti E, Pellino G, Nikolau S, et al. Comparison of guidelines for the management of rectal cancer. B7S Open 2018;2:433-451. 